\title{
Surgical Management of Chronic Rhinosinusitis in Cystic Fibrosis
}

\author{
Zhong Zheng, Chetan Safi and David A. Gudis * \\ Department of Otolaryngology-Head and Neck Surgery, Columbia University Irving Medical Center, \\ New York, NY 10032, USA; zz2618@cumc.columbia.edu (Z.Z.); cys9028@nyp.org (C.S.) \\ * Correspondence: dag62@cumc.columbia.edu; Tel.: +1-212-305-8555
}

Received: 16 January 2019; Accepted: 5 April 2019; Published: 7 April 2019

\begin{abstract}
Cystic fibrosis patients frequently develop chronic rhinosinusitis as a result of their propensity to form inspissated mucus and impairment of mucociliary clearance. They exhibit variable symptom burden even in the setting of positive radiographic and endoscopic findings. Current evidence suggests a positive effect of managing sinonasal disease on pulmonary health. Topical antimicrobial and mucolytic therapies are frequently required to manage the disease with surgery reserved for refractory cases. Endoscopic sinus surgery has been demonstrated to be safe and efficacious in controlling symptoms of chronic rhinosinusitis in patients with comorbid cystic fibrosis. However, the impact of surgery on pulmonary health remains an active area of investigation. In addition, a growing body of research has suggested a more extended surgical approach creating large sinonasal cavities with gravity-dependent drainage pathways, followed by adjuvant medical therapies, as an ideal strategy to optimally control disease and prevent pulmonary exacerbations. In this manuscript, we provide an up-to-date review of current evidence in the surgical management of chronic rhinosinusitis in cystic fibrosis patients.
\end{abstract}

Keywords: rhinosinusitis; cystic fibrosis; endoscopic sinus surgery; medial maxillectomy

\section{Introduction}

Cystic fibrosis (CF) is an autosomal recessive disease characterized by a defect in the cystic fibrosis transmembrane conductance regulator (CFTR) gene on chromosome 7, which encodes for a chloride ion transporter on the apical membrane of epithelial cells. It predominantly affects the Caucasian population, with a prevalence of $\sim 30,000$ patients in the United States and $\sim 70,000$ patients worldwide [1]. As a result of defective trans-membrane anion transport, CF patients develop increased epithelial sodium and water resorption and produce thick inspissated secretions, which then cause mucociliary stasis, chronic inflammation, bacterial colonization, and infection in multiple organ systems, including the upper and lower airways. The average life expectancy of CF patients is 48.5 years, and the majority of CF-related mortalities are due to progressive pulmonary decline, with many patients eventually requiring lung transplantation [2,3].

Impaired sinonasal mucociliary clearance mechanisms predispose CF patients to develop chronic rhinosinusitis (CRS) and nasal polyposis. On computed tomography (CT), CF patients also have under-developed paranasal sinuses due to chronic inflammation, further complicating ventilation and drainage [4]. Furthermore, a growing body of research has demonstrated a significant link between sinonasal and pulmonary health with regards to bacterial colonization, with an $80 \%$ concordance of bacterial isolates from sinonasal and bronchoalveolar lavages (BAL) [5]. The mainstays of medical therapies for CF CRS include oral and topical antibiotics directed at Pseudomonas aeruginosa and Staphyloccocus aureus species, topical mucolytic agents, and more recently CFTR modulators [6]. Refractory to medical therapy, endoscopic sinus surgery (ESS) has been shown to improve sinonasal 
symptoms and quality of life outcomes and reduce pulmonary bacterial colonization [5,7]. However, currently available data on the effect of ESS on pulmonary functions are conflicting $[5,8]$. In this manuscript, our objective is to provide an up-to-date review of current evidence in the surgical management of CRS in CF patients.

\section{Unified Airway Health}

Drawing a parallel with the unified airway model in reactive airway disease, mounting evidence has demonstrated a significant correlation between the health of paranasal sinuses and lungs. Studies have shown a possible mechanism of bacterial translocation from upper to lower airways. Therefore, in addition to alleviating symptoms of CRS in CF, ESS has the added benefit of creating an open and accessible sinonasal cavity to topical therapies and reducing bacterial seeding of the lungs. Furthermore, the reduction or eradication of pulmonary pathogenic colonization is critically important to prevent allograft rejection in post-lung transplant CF patients. A recent study compared microbiota composition from the sinuses and lung brushings using 16s RNA sequencing techniques, and microbiome diversity was found to be diminished in both the sinuses and lungs in CF CRS patients. Interestingly, non-CF CRS patients had distinct niches of microorganisms in their upper versus lower airways, while CF CRS patients had indistinguishable niches at both anatomic sites, lending further evidence to the theory of sinonasal cavity as a reservoir for bacterial translocation to lower airway in CF patients [9]. Walter and colleagues followed a cohort of 11 CF patients pre- and post-lung transplant, and identical P. aeruginosa isolates were seen in all patients within the sinuses and lungs [10]. Moreover, Mainz et al evaluated $182 \mathrm{CF}$ patients and demonstrated significant genotypic concordance of $P$. aeruginosa and S. aureus isolates in upper and lower airways. Genetically identical strains of P. aeruginosa and S. aureus were identified in 31 of 36 and 23 of 24 patients, respectively. In addition, patients with positive $P$. aeruginosa sputum cultures were 88 times more likely to be colonized in the upper airway with the same bacterial pathogen [11]. In a different study, the same authors also found rapid colonization of new donor lungs with P. aeruginosa that was genetically identical to pre-transplant isolates within four weeks post-transplantation, and this colonization could be prevented by topical colistin antibiotic therapy [12]. A different group demonstrated the median time of recovery of $P$. aeruginosa species from CF lung transplant patients was 15 days post -peratively, as compared to 158 days in non-CF recipients. Histologically, evidence of Pseudomonas infection was also detected earlier at post-operative day (POD) \#10, (vs. POD \#261 in non-CF) and at a higher rate (13/44 in CF vs. $3 / 21$ in non-CF) [13]. Overall, although currently available evidence is limited by its retrospective nature and mostly small case series, with many including both surgical and medical controls; however, a correlation between sinonasal and pulmonary health with regards to pathogenic bacterial colonization has been suggested. Thus, ESS plays an important role in reducing the bacterial burden in the upper airway to prevent subsequent seeding of the lower airway.

\section{Surgical Management}

Although almost all CF patients have endoscopic and radiological findings of sinonasal disease and a majority of them have extensive nasal polyposis, patient-reported subjective symptoms are variable at less than $20 \%$ [2]. Despite appropriate medical therapy, 20 to $60 \%$ of CF patients go on to require ESS [2]. In a retrospective review, Brook et al. showed that prior history of ESS and severe CFTR mutations are predictive of ESS while Sinonasal Outcome Test (SNOT)-22 score was not [14]. In a different study, CF patients with nasal polyposis, prior history of ESS, lower forced expiratory volume in one second (FEV1), higher Lund-Mackay score, and higher SNOT-22 score was more likely to elect up-front ESS versus medical therapy. Furthermore, a delay in surgery did not affect post-operative improvement [15]. There are no current guidelines specifically for the management of CF CRS, and patient selection for ESS should follow previously established recommendations for the management of CRS [16] with the additional consideration for reducing pulmonary pathogen colonization, especially in post-lung transplant CF patients. 
Radiographically, CF patients have a high prevalence of frontal aplasia, and maxillary, ethmoid, and sphenoid hypoplasia. Sclerotic sphenoethmoidal partitions are also commonly found. Interestingly, other important anatomic variants were seen differentially in CF patients: Haller cells and concha bullosa were rarely seen, whereas Onodi cells were more frequently observed [4,17]. Careful pre-operative evaluation of $\mathrm{CT}$ findings is critical in avoiding complications and ensuring complete removal of all bony partitions. Complete ESS is especially important in CF CRS, as inspissated secretions may be trapped in partially removed partitions. A recent study also demonstrated high-risk CF mutations are associated with more severe radiographic findings as measured by modified Lund-Mackay scores, as well as higher prevalence of sinus hypoplasia/aplasia [18]. An understanding of CF pathophysiology is important in the surgical management of CF CRS patients to ensure surgical success. In our experience, intra-operative image guidance can be an invaluable tool due to anatomic differences in CF patients, especially in revision cases. However, its use should be judicious and always correlated with knowledge of surgical landmarks. Lastly, a cohort of pediatric CF patients who underwent ESS during and after facial growth spurts was followed prospectively for over 10 years, and no significant differences in cephalometric measurements were demonstrated, which corroborates previous findings on the safety of ESS on pediatric facial growth [19].

Large systematic reviews have demonstrated a definitive benefit of ESS on patient-reported quality of life (QoL) outcomes, while the effect of sinus surgery on pulmonary function tests (PFTs) have yielded conflicting results to date. Khalid et al. demonstrated significant improvement in QoL as measured by the Rhinosinusitis Disability Index (RSDI) in CF patients after ESS that was comparable to control patients, even though CF patients had worse pre-operative CT and endoscopic findings [20]. In one systematic review, Macdonald et al. found that ESS consistently improved sinonasal symptoms in CF patients, and some evidence existed for reduced days of hospitalization for pulmonary exacerbations and usage of intravenous antibiotic therapy. However, no significant changes in pulmonary function tests, including FEV1, were identified [21,22]. Another systematic review similarly demonstrated that ESS led to improved sinonasal symptoms and endoscopic scores, while PFTs were improved in $3 / 8$ level four studies [5]. Kovell et al. demonstrated an improvement in PFTs in pediatric CF patients following ESS, although some of the benefits were mitigated by lower socioeconomic status [23]. Khalfoun and colleagues found that the decline in FEV1 was prevented by ESS in patients with moderate to severe lung disease [8]. Large systematic reviews evaluated the entire aggregate of $\mathrm{CF}$ patients; subgroup analysis of high versus low-risk mutations may provide additional insights and can be an area of future research. A study by Halderman and colleagues alluded to this and demonstrated differential responses of PFTs to ESS in homozygous versus heterozygous F5018del CF patients [24].

Endoscopic sinus surgery also plays a critical role in reducing or eradicating pulmonary colonization of pathogens in CF patients. Aanaes and colleagues prospectively followed a cohort of 106 CF patients after ESS with adjuvant systemic and topical therapy, and they demonstrated reduced pulmonary colonization with CF pathogens at 6 months [7]. Furthermore, the percentage of patients without any gram-negative bacteria colonization in the lungs increased from $15 \%$ to $33 \%$ at 3 years. Although overall pulmonary decline was observed for the cohort, a small percentage of patients had stable lung functions [25]. Holzmann et al. studied the effects of ESS on 37 post-lung transplant CF patients and found a significant correlation between sinus culture positivity and BAL positivity. Successful ESS (defined as less than 3 post-operative sinus aspirates with significant bacterial growth) was associated with significantly reduced incidence of lower airway exacerbations and a trend toward decreased bronchiolitis obliterans syndrome (BOS) [26]. Similarly, Vital et al. demonstrated a significant correlation between chronic sinonasal colonization and lung allograft infection rates in CF patients after lung transplantation and sinus surgery. Furthermore, ESS and daily saline irrigation were successful in eliminating P. aeruginosa colonization in more than a third of patients [27]. The absence of persistent airway pathogenic colonization was associated with less frequent and delayed development of BOS and increased overall survival [28]. In contrast, Leung and colleagues found 
that pre-transplant ESS did not prevent post-transplant Pseudomonas re-colonization and did not affect overall survival [29].

\section{Extended Sinus Surgery}

Recently, modified endoscopic medial maxillectomy (MEMM) has been increasingly performed for recalcitrant maxillary sinus disease. This technique is especially useful in CF patients, allowing large cavities for gravity-dependent drainage, improved topical medication delivery, and access for office-based debridement or polypectomy. A recent study combining MEMM with mucosal stripping of maxillary sinuses and total ethmoidectomy showed significant volume reduction of maxillary sinuses through osteoneogenesis, which the authors proposed as a mechanism for decreased mucus accumulation, thus, chronic bacterial colonization of the sinonasal cavity [30]. The sustained improvement of sinonasal symptoms after MEMM has been demonstrated for up to 6.9 years, although the patient population in this study was more heterogeneous and included all patients with recalcitrant chronic maxillary sinusitis [31].

According to Shatz, a combined Caldwell-Luc approach and medial maxillectomy for CF CRS patients with prior ESS failure were efficacious in reducing episodes of hospitalizations and need for IV antibiotics. Interestingly, FEV1 was significantly improved at 6 months in his cohort of 15 patients [32]. Virgin and colleagues followed a cohort of 22 patients after MEMM and found significant improvement in patient-reported symptom scores, as well as a decreased number of pulmonary exacerbations requiring hospitalization with 1 year follow up [1].

CF patients often have aplastic or hypoplastic frontal sinuses; however, the modified endoscopic Lothrop procedure is a consideration in recalcitrant frontal sinus disease in CF patients. Jaberoo et al. described a series of two CF patients who safely underwent modified Lothrop procedure with good symptomatic improvement [33]. Although the safety and efficacy can be extrapolated from non-CF CRS literature, larger prospective studies are needed to evaluate outcomes of Draf 3 procedures in CF CRS patients.

\section{Post-Operative Adjuvant Therapy}

Similar to our understanding of non-CF CRS, a combined approach of endoscopic sinus surgery followed by post-surgical adjuvant medical therapy represents the most optimal treatment for disease control in CF CRS. Aanaes et al. demonstrated that intensive post-operative nasal saline irrigation, topical colistin, and office debridement following ESS eradicated pathogenic bacteria in $67 \%$ of operated sinuses 6-months post-operatively, with effect sustained up to 3 years [34]. Similarly, the frequency of BAL negativity for CF pathogens increased by $150 \% 1$ year after sinus surgery with adjuvant therapy [7]. Moss and colleagues studied the effect of topical tobramycin irrigation after ESS and found a reduction in the need for future surgical interventions [35]. Combining complete ESS with MEMM and a post-operative regimen that included both oral and topical antibiotic and steroid therapy, Virgin et al. showed a significant reduction of symptoms and hospitalizations for pulmonary exacerbations [1]. Cimmino and colleagues performed a small randomized double-blind placebo-controlled trial of $24 \mathrm{CF}$ patients who underwent sinus surgery and then maintained on dornase alfa therapy, and they demonstrated a significantly improved FEV1 compared to control patients. In addition, patient-reported symptom scores and Lund-Kennedy endoscopic scores were both improved over placebo [36].

\section{Summary}

The treatment of chronic rhinosinusitis with comorbid cystic fibrosis is complex and challenging. High disease burden found on endoscopic or radiographic examination often does not correlate with patient self-reported symptoms. Currently available data are limited to mostly case series, and further larger prospective studies are much-needed. Endoscopic sinus surgery has been shown to improve sinonasal and pulmonary bacterial colonization, as well as alleviating patient symptoms. The effects 
of sinus surgery on pulmonary functions are less clear. Despite a paucity of high-quality data and lack of an established treatment algorithm, increasing research has suggested that a multi-disciplinary approach with extensive sinus surgery creating gravity dependent drainage pathways, combined with adjunct topical and medical therapies, offer the most optimal treatment strategy for CF CRS patients.

Funding: This research received no external funding.

Conflicts of Interest: The authors declare no conflict of interest.

\section{References}

1. Virgin, F.W.; Rowe, S.M.; Wade, M.B.; Gaggar, A.; Leon, K.J.; Young, K.R.; Woodworth, B.A. Extensive surgical and comprehensive postoperative medical management for cystic fibrosis chronic rhinosinusitis. Am. J. Rhinol. Allergy 2012, 26, 70-75. [CrossRef] [PubMed]

2. Tipirneni, K.E.; Woodworth, B.A. Medical and Surgical Advancements in the Management of Cystic Fibrosis Chronic Rhinosinusitis. Curr. Otorhinolaryngol. Rep. 2017, 5, 24-34. [CrossRef]

3. Yang, C.; Chilvers, M.; Montgomery, M.; Nolan, S.J. Dornase alfa for cystic fibrosis. Cochrane Database Syst. Rev. 2016.

4. Orlandi, R.R.; Wiggins, R.H. Radiological Sinonasal Findings in Adults with Cystic Fibrosis. Am. J. Rhinol. 2009, 23, 307-311. [CrossRef]

5. $\quad$ Liang, J.; Higgins, T.S.; Ishman, S.; Boss, E.F.; Benke, J.R.; Lin, S.Y. Surgical management of chronic rhinosinusitis in cystic fibrosis: A systematic review. Int. Rhinol. 2013, 3, 814-822. [CrossRef]

6. Illing, E.A.; Woodworth, B.A. Management of the Upper Airway in Cystic Fibrosis. Curr. Opin. Pulm. Med. 2014, 20, 623-631. [CrossRef]

7. Aanaes, K.; Johansen, H.; Skov, M.; Buchvald, F.; Hjuler, T.; Pressler, T.; Hoiby, N.; Nielsen, K.; Von Buchwald, C. Clinical effects of sinus surgery and adjuvant therapy in cystic fibrosis patients-Can chronic lung infections be postponed? Rhinol. J. 2013, 51, 222-230. [CrossRef]

8. Khalfoun, S.; Tumin, D.; Ghossein, M.; Lind, M.; Hayes, D., Jr.; Kirkby, S. Improved lung function after sinus susgery in cystic fibrosis patients with moderate obstruction. Otolaryngol. Head Neck Surg. 2018, 158, 381-385. [CrossRef] [PubMed]

9. Pletcher, S.D.; Goldberg, A.N.; Cope, E.K. Loss of Microbial Niche Specificity between the Upper and Lower Airways in Patients with Cystic Fibrosis. Laryngoscope 2018, 129, 544-550. [CrossRef]

10. Walter, S.; Gudowius, P.; Bosshammer, J.; Romling, U.; Weissbrodt, H.; Schürmann, W.; Von Der Hardt, H.; Tummler, B. Epidemiology of chronic Pseudomonas aeruginosa infections in the airways of lung transplant recipients with cystic fibrosis. Thorax 1997, 52, 318-321. [CrossRef] [PubMed]

11. Mainz, J.G.; Naehrlich, L.; Schien, M.; Käding, M.; Schiller, I.; Mayr, S.; Schneider, G.; Wiedemann, B.; Wiehlmann, L.; Cramer, N.; et al. Concordant genotype of upper and lower airways P aeruginosa and S aureus isolates in cystic fibrosis. Thorax 2009, 64, 535-540. [CrossRef]

12. Mainz, J.G.; Hentschel, J.; Schien, C.; Cramer, N.; Pfister, W.; Beck, J.; Tummler, B. Sinonasal persistence of Pseudomonas aeruginosa after lung transplantation. J. Cyst. Fibros. 2012, 11, 158-161. [CrossRef]

13. Nunley, D.R.; Grgurich, W.; Iacono, A.T.; Yousem, S.; Ohori, N.P.; Keenan, R.J.; Dauber, J.H. Allograft Colonization and Infections with Pseudomonas in Cystic Fibrosis Lung Transplant Recipients. Chest 1998, 113, 1235-1243. [CrossRef] [PubMed]

14. Brook, C.D.; Maxfield, A.Z.; Ahmed, H.; Sedaghat, A.R.; Holbrook, E.H.; Gray, S.T. Factors influencing the need for endoscopic sinus surgery in adult patients with cystic fibrosis. Am. J. Rhinol. Allergy 2017, 31, 44-47. [CrossRef]

15. Ayoub, N.; Thamboo, A.; Habib, A.-R.; Nayak, J.V.; Hwang, P.H.; Habib, A. Determinants and outcomes of upfront surgery versus medical therapy for chronic rhinosinusitis in cystic fibrosis. Int. Rhinol. 2017, 7, 450-458. [CrossRef]

16. Rosenfeld, R.M.; Piccirillo, J.F.; Chandrasekhar, S.S.; Brook, I.; Ashok Kumar, K.; Kramper, M.; Orlandi, R.R.; Palmer, J.N.; Patel, Z.M.; Peters, A.; et al. Clinical practice guidelines (update): Adult sinusitis. Otolaryngol. Head Neck Surg. 2015, 152, S1-S39. [CrossRef] [PubMed]

17. Eggesbø, H.; Søvik, S.; Dølvik, S.; Eiklid, K.; Kolmannskog, F. CT characterization of developmental variations of the paranasal sinuses in cystic fibrosis. Acta Radiol. 2001, 42, 482-493. [CrossRef] 
18. Halderman, A.A.; Lee, S.; London, N.R.; Day, A.; Jain, R.; Moore, J.A.; Lin, S.Y. Impact of high- versus low-risk genotype on sinonasal radiographic disease in cystic fibrosis. Laryngoscope 2018, 129, 788-793. [CrossRef] [PubMed]

19. Van Peteghem, A.; Clement, P. Influence of extensive functional endoscopic sinus surgery (FESS) on facial growth in children with cystic fibrosis. Int. J. Pediatr. Otorhinolaryngol. 2006, 70, 1407-1413. [CrossRef] [PubMed]

20. Khalid, A.N.; Smith, T.; Mace, J.C. Outcomes of sinus surgery in adults with cystic fibrosis. Otolaryngol. Neck Surg. 2009, 141, P115. [CrossRef]

21. I MacDonald, K.; Gipsman, A.; Magit, A.; Fandino, M.; Massoud, E.; Witterick, I.J.; Hong, P. Endoscopic sinus surgery in patients with cystic fibrosis: A systematic review and meta-analysis of pulmonary function. Rhinol. J. 2012, 50, 360-369. [CrossRef]

22. Henriquez, O.A.; Wolfenden, L.L.; Stecenko, A.; DelGaudio, J.M.; Wise, S.K. Endoscopic Sinus Surgery in Adults With Cystic Fibrosis. Arch. Otolaryngol. Head Neck Surg. 2012, 138, 1167-1170. [CrossRef] [PubMed]

23. Kovell, L.C.; Wang, J.; Ishman, S.L.; Zeitlin, P.L.; Boss, E.F. Cystic fibrosis and sinusitis in children: Outcomes and socioeconomic status. Otolaryngol. Head Neck Surg. 2011, 145, 146-153. [CrossRef]

24. Halderman, A.A.; West, N.; Benke, J.; Roxbury, C.R.; Lin, S.Y. F508del genotype in endoscopic sinus surgery: Do differences in outcomes exist between genotypic subgroups? Int. Forum Allergy Rhinol. 2017, 7, 459-466. [CrossRef]

25. Alanin, M.C.; Aanaes, K.; Høiby, N.; Pressler, T.; Skov, M.; Nielsen, K.G.; Taylor-Robinson, D.; Waldmann, E.; Krogh Johansen, H.; von Buchwald, C. Sinus surgery postpones chronic Gram-negative lung infection. Rhinology 2016, 54, 206-213. [CrossRef] [PubMed]

26. Holzmann, D.; Speich, R.; Kaufmann, T.; Laube, I.; Russi, E.W.; Simmen, D.; Weder, W.; Boehler, A. Effects of sinus surgery in patients with cystic fibrosis after lung transplantation: A 10-year experience. Transplantation 2004, 77, 134-136. [CrossRef] [PubMed]

27. Vital, D.; Hofer, M.; Boehler, A.; Holzmann, D. Posttransplant sinus surgery in lung transplant recipients with cystic fibrosis: A single institutional experience. Eur. Arch. Otorhinolaryngol. 2013, 270, 135-159. [CrossRef]

28. Vital, D.; Hofer, M.; Benden, C.; Holzmann, D.; Boehler, A. Impact of Sinus Surgery on Pseudomonal Airway Colonization, Bronchiolitis Obliterans Syndrome and Survival in Cystic Fibrosis Lung Transplant Recipients. Respiration 2013, 86, 25-31. [CrossRef]

29. Leung, M.-K.; Rachakonda, L.; Weill, D.; Hwang, P.H. Effects of Sinus Surgery on lung Transplantation Outcomes in Cystic Fibrosis. Am. J. Rhinol. 2008, 22, 192-196. [CrossRef]

30. Buras, M.; Simoncini, A.; Gungor, A. Auto-obliteration of maxillary sinuses through osteogenesis in children with cystic fibrosis: A possible new way to reduce morbidities. Am. J. Otolaryngol. 2018, 39, 737-740. [CrossRef]

31. Costa, M.L.; Psaltis, A.J.; Nayak, J.V.; Hwang, P.H. Long-term outcomes of endoscopic maxillary mega-antrostomy for refractory chronic maxillary sinusitis. Int. Forum Allergy Rhinol. 2015, 5, 60-65. [CrossRef] [PubMed]

32. Shatz, A. Management of recurrent sinus disease in children with cystic fibrosis: A combined approach. Otolaryngol. Head Neck Surg. 2006, 135, 248-252. [CrossRef]

33. Jaberoo, M.C.; Pulido, M.A.; Saleh, H.A. Modified Lothrop procedure in cystic fibrosis patients: Does it have a role? J. Laryngol. Otol. 2012, 127, 666-669. [CrossRef]

34. Aanaes, K.; Hjuler, T.; Alanin, M.; Von Buchwald, C.; Skov, M.; Johansen, H.K. The Effect of Sinus Surgery with Intensive follow-up on Pathogenic Sinus Bacteria in Patients with Cystic Fibrosis. Am. J. Rhinol. 2013, 27, e1-e4. [CrossRef]

35. Moss, R.B.; King., V.V. Management of sinusitis in cystic fibrosis by endoscopic surgery and serial antimicrobial lavage. Arch. Otolaryngol. Head Neck Surg. 1995, 121, 566-572. [CrossRef]

36. Cimmino, M.; Nardone, M.; Cavaliere, M.; Plantulli, A.; Sepe, A.; Esposito, V.; Mazzarella, G.; Raia, V. Dornase Alfa as Postoperative Therapy in Cystic Fibrosis Sinonasal Disease. Arch. Otolaryngol. Head Neck Surg. 2005, 131, 1097-1101. [CrossRef] [PubMed]

(C) 2019 by the authors. Licensee MDPI, Basel, Switzerland. This article is an open access article distributed under the terms and conditions of the Creative Commons Attribution (CC BY) license (http:/ / creativecommons.org/licenses/by/4.0/). 